\title{
Aqueous extract of Combretum molle boughs ameliorates hyperglycaemia and hyperlipidemia in sucrose-induced insulin resistant rats
}

\author{
David Miaffo $^{*^{* \mathbb{D}}}$, Fidèle Ntchapda ${ }^{2}$, Sylvie Léa Wansi ${ }^{3}$, Sylviane Laure Kamani Poualeu ${ }^{3}$, Albert Kamanyi ${ }^{3}$ \\ ${ }^{1}$ Department of Life and Earth Sciences, Higher Teachers' Training College, University of Maroua, Far North Region, Cameroon \\ ${ }^{2}$ Department of Biological Sciences, Faculty of Sciences, University of Ngaoundéré, Adamaoua Region, Cameroon \\ ${ }^{3}$ Department of Animal Biology, Faculty of Sciences, University of Dschang, West Region, Cameroon
}

\section{A R T I C L E I N F O}

Article Type:

Original Article

\section{Article History:}

Received: 30 May 2019

Accepted: 22 June 2019

\section{Keywords:}

Combretum molle

Diabetes

Insulin resistance

Hyperglyceamia

Hyperlipidemia

Sucrose

\begin{abstract}
A B S T RA C T
Introduction: Combretum molle R.B/G.Don (Combretaceae) is distributed especially in tropical Africa and used in treatment various diseases including diabetes. The aim of the present study was to evaluate the effects of aqueous extract from C. molle boughs (CMAE) on hyperglycemia and dyslipidemia in insulin resistant rats.

Methods: Animals were divided into 5 groups and treated for 30 days. Control group received distilled water, sucrose group received 30\% sucrose, standard group received 30\% sucrose plus metformin $(40 \mathrm{mg} / \mathrm{kg}$ ), and others groups received 30\% sucrose plus CMAE (250 and $500 \mathrm{mg} / \mathrm{kg}$ ). Body weight, food and water intake were evaluated each 10 days for 30 days. Glucose tolerance test was performed on the 30th day of the experiment. Later on, animals were sacrificed and blood was collected for the determination of the concentration of glucose, lipids and insulin.

Results: The body weight and food intake of the rats receiving $500 \mathrm{mg} / \mathrm{kg}$ of extract decreased significantly on the 30th day of the experiment. CMAE caused a significant reduction of insulin, glucose, cholesterol, triglycerides and low-density lipoprotein cholesterol levels compared to the sucrose lot. However, the extract $(250$ and $500 \mathrm{mg} / \mathrm{kg}$ ) showed a significant increase in high-density lipoprotein cholesterol. CMAE induced a significant decrease in postprandial glycaemia.

Conclusion: CMAE improved postprandial hyperglycemia and hyperlipidemia in insulin resistant rats. Consequently, CMAE may be able to delay onset of insulin resistance, and reduce the risks and complications of type 2 diabetes.
\end{abstract}

Implication for health policy/practice/research/medical education:

The aqueous extract of Combretum molle boughs may be able to delay onset of insulin resistance, and reduce the risks and complications of type 2 diabetes. Therefore, its use in diabetic patients is recommended.

Please cite this paper as: Miaffo D, Ntchapda F, Wansi SL, Kamani Poualeu SL, Kamanyi A. Aqueous extract of Combretum molle boughs ameliorates hyperglycaemia and hyperlipidemia in sucrose-induced insulin resistant rats. J Herbmed Pharmacol. 2019;8(4):328-332. doi: 10.15171/jhp.2019.48.

\section{Introduction}

Insulin resistance is associated with a decrease in insulin sensitivity in the target tissues (liver, muscles and adipose tissue) (1). Insulin resistance is at the heart of the metabolic syndrome and appears to be a major element of many pathologies such as diabetes, high blood pressure, heart and vessel diseases (2). Thus, diabetes mellitus is a public health problem because all these diseases are increasing worldwide, both in industrialized and developing countries. Indeed, globally, approximately 422 million diabetics were identified in 2014 and by 2030, about 430 million people will have this disease (3). Diabetes deaths were 1.5 million in 2012 and will reach 3.7 million in 2040 (4).

High-sucrose intake was shown to contribute syndromes such as hyperlipidemia, glucose intolerance, hypertension, 
and cardiovascular complications (5). A diet too rich in sucrose can reduce the sensitivity of target tissues to insulin and therefore can induce type 2 diabetes mellitus in animals (6). The treatment of diabetes relies on the administration of insulin and the taking of oral antidiabetic agents such as metformin, sulphonylureas, glinides, alphaglucosidase inhibitors, etc. These medications have many adverse side effects (hypoglycemia, coma, ketoacidosis, gastrointestinal disorders, headache, nausea, etc.) and significant risks of cardiovascular diseases (7).

The traditional pharmacopoeia offers an alternative solution to most diseases (8). Nowadays, different parts of plants are traditionally used to treat diabetic patients. Combretum molle (Combretaceae) is a graceful deciduous shrub 3-13 $\mathrm{m}$ in height (9), generally widespread in tropical Africa (10) and widely used in African traditional medicine as antifungal, antimicrobial, antioxidant, antiinflammatory and antidiabetic $(11,12)$. A literature review revealed no studies of the hypoglycemic activity of the aqueous extract of CMAE boughs in high sucrose-fed experimental animals. The aim of the present study was to explore the activity of CMAE on hyperglycemia and hyperlipidemia in sucrose-induced insulin resistance rats.

\section{Materials and Methods}

\section{Chemicals}

Kits for biochemical assays were purchased from SigmaAldrich (St. Louis, USA). Sucrose and D-glucose were purchased from Edu-Lab Biology Kit (Bexwell, Norfolk, UK). All chemicals and drugs were obtained commercially in analytical grade.

\section{Plant material and extraction}

The fresh boughs of $C$. molle were collected in December 2018 from Moutourwa, Cameroon. Botanical identification was carried out at the National Herbarium, Yaoundé, Cameroon (HNC). Voucher specimen was maintained in the $\mathrm{HNC}$ and registered under $\mathrm{N}^{\circ}$ 433724NHC. The boughs of C. molle were washed, chopped into small pieces, dried under shade and finely powdered. Two hundred grams (200 g) of fine powder of C. molle were added to $500 \mathrm{~mL}$ of distilled water and the whole content was boiled for 15 minutes. After cooling, the crude extract obtained was filtered using Whatman paper and the filtrate was evaporated in an oven for 72 hours at a temperature of $45^{\circ} \mathrm{C}$ to give a yield of $9.64 \%$ of dry extract.

\section{Experimental animals}

Male Wistar strain rats (220 and $250 \mathrm{~g}$ ) were provided by the animal house of the Department of Animal Biology of the Faculty of Science at the University of Dschang in the polystyrene cages ( 5 rats per cage). Before being used for the various tests, they were acclimated for 7 days to laboratory conditions $\left(24 \pm 2^{\circ} \mathrm{C}, 50-55 \%\right.$ humidity and
$12 \mathrm{~h}$ light/dark cycles). They received daily drinking water and normal laboratory standard pelleted diet ad libitum.

\section{Experimental design}

Thirty rats were distributed into 5 different treatment groups $(n=6)$ for 30 days as follows: Control normal group received distilled water, sucrose group received $30 \%$ sucrose solution (Suc), standard group received 30\% sucrose plus metformin (Suc $+\mathrm{Met}$ ) at doses of $40 \mathrm{mg} / \mathrm{kg}$, and others groups received $30 \%$ sucrose plus CMAE (Suc + Ext) at doses of 250 and $500 \mathrm{mg} / \mathrm{kg}$. Sucrose solution was administered as drinking water and treatments (either vehicle, standard drug or extract) were administered orally using intragastric tube. Food, water intake and body weight were evaluated on 0,10 th, 20th and 30th days of the experiment.

\section{Oral glucose tolerance test (OGTT)}

The glucose tolerance test was performed on the last day of the experiment. Animals were fasted for $12 \mathrm{~h}$ and D-glucose solution $(2 \mathrm{~g} / \mathrm{kg})$ was orally given to the rats. Glycaemia was determined every 30 minutes for 2 hours after administration of D-glucose from tail vein.

\section{Biochemical estimation}

After the OGTT, animals were fasted overnight and the blood was obtained by decapitation of rats anesthetized with diazepam (10 mg/kg bw, i.p.) and ketamine $(50 \mathrm{mg} /$ kg bw, i.p.). Dry tubes containing collected blood were centrifuged at $3000 \mathrm{rpm}$ for $15 \mathrm{~min}$. The obtained serum was stored at $-20^{\circ} \mathrm{C}$ for the estimation of biochemical parameters. Fasting blood glucose was evaluated at the end of the experiment. Serum insulin was measured using ELISA kit. HOMA-IR was calculated as follows: [Serum insulin $(\mu \mathrm{g} / \mathrm{L}) \times$ Blood glucose $(\mathrm{mg} / \mathrm{dL})] / 22.5$. Total cholesterol (TC), triglycerides (TG), high-density lipoprotein cholesterol (HDL-C) and low-density lipoprotein cholesterol (LDL-C)were performed as per the respective kit inserts.

\section{Statistical analysis}

All data were presented as mean \pm SEM. Statistical analysis was carried out by one-way ANOVA followed by Tukey's post hoc using GraphPad Prism version 5.0. Values of $P<$ 0.05 were considered significant.

\section{Results}

Effect of CMAE on body weight, food and water consumption

Table 1 shows the effect of repeated administration of CMAE on body weight, food and water consumption in insulin resistance rats. There was no important variation between the body weight, food and water intake of the control, standard and sucrose groups rats for 30 days of experiment. Body weight decreased significantly in rats 
Table 1. Effect of Combretum molle on body weight, water and food consumption in insulin resistant rats

\begin{tabular}{|c|c|c|c|c|c|c|}
\hline & Groups time (days) & Normal control & $\begin{array}{l}\text { Disease } \\
\text { control }\end{array}$ & $\begin{array}{l}\text { Suc + Met } \\
40 \mathrm{mg} / \mathrm{kg}\end{array}$ & $\begin{array}{c}\text { Suc + Ext } \\
250 \mathrm{mg} / \mathrm{kg}\end{array}$ & $\begin{array}{c}\text { Suc + Ext } \\
500 \mathrm{mg} / \mathrm{kg}\end{array}$ \\
\hline \multirow{4}{*}{ Body weight (g) } & 0 & $231.00 \pm 4.43$ & $232.18 \pm 4.39$ & $231.33 \pm 3.26$ & $233.34 \pm 4.06$ & $235.33 \pm 3.95$ \\
\hline & 10 & $238.67 \pm 3.99$ & $239.66 \pm 4.81$ & $241.83 \pm 3.39$ & $242.82 \pm 3.67$ & $244.00 \pm 4.15$ \\
\hline & 20 & $247.67 \pm 4.10$ & $251.16 \pm 6.03$ & $250.34 \pm 2.78$ & $249.17 \pm 3.20$ & $248.17 \pm 3.97 b$ \\
\hline & 30 & $250.00 \pm 4.07$ & $252.67 \pm 5.91$ & $252.50 \pm 3.11$ & $251.33 \pm 3.59$ & $251.50 \pm 4.04 a$ \\
\hline \multirow{4}{*}{ Food intake (g) } & 0 & $18.92 \pm 0.37$ & $20.25 \pm 0.66$ & $20.16 \pm 0.47$ & $19.48 \pm 0.52$ & $18.40 \pm 1.43$ \\
\hline & 10 & $18.78 \pm 0.97$ & $18.02 \pm 1.00$ & $16.90 \pm 0.97$ & $16.22 \pm 1.11$ & $16.52 \pm 0.66$ \\
\hline & 20 & $18.68 \pm 0.78$ & $17.20 \pm 1.11$ & $18.58 \pm 0.96$ & $16.45 \pm 1.05$ & $16.18 \pm 0.93$ \\
\hline & 30 & $16.58 \pm 0.97$ & $19.55 \pm 1.00$ & $17.07 \pm 0.79$ & $15.07 \pm 0.79 b$ & $15.72 \pm 1.01 b$ \\
\hline \multirow{4}{*}{ Water intake $(\mathrm{mL})$} & 0 & $41.31 \pm 2.17$ & $42.55 \pm 3.78$ & $40.63 \pm 3.54$ & $40.42 \pm 2.66$ & $37.02 \pm 2.50$ \\
\hline & 10 & $39.57 \pm 4.11$ & $36.48 \pm 2.93$ & $37.55 \pm 2.46$ & $37.88 \pm 2.60$ & $32.20 \pm 1.11$ \\
\hline & 20 & $40.78 \pm 2.48$ & $38.77 \pm 1.65$ & $37.20 \pm 3.00$ & $35.60 \pm 2.68$ & $35.65 \pm 3.22$ \\
\hline & 30 & $40.32 \pm 3.22$ & $38.68 \pm 2.04$ & $38.60 \pm 3.31$ & $32.88 \pm 2.87$ & $35.87 \pm 2.72$ \\
\hline
\end{tabular}

Data are mean \pm SEM ( $n=6$ in each group). ${ }^{\text {a }} P<0.05$; ${ }^{\text {b }} P<0.01$ significantly different compared to disease control group. Sucrose + Metformin (Suc + Met); Sucrose + Extract (Suc + Ext).

receiving $500 \mathrm{mg} / \mathrm{kg}$ of extract at days $20(P<0.01)$ and $30(P<0.05)$ of the experiment, compared with untreated insulin resistant rats. Similarly, at the end of the treatment period (day 30), animals treated with 250 and $500 \mathrm{mg} /$ $\mathrm{kg}$ of extract showed a significant $(P<0.01)$ reduction in dietary intake. However, water consumption was not different significantly in all experimental animals for 30 days.

Effect of CMAE on glycaemia, insulin level and HOMAIR index

As shown in Table 2, a significant $(P<0.001)$ increase in blood glucose, insulin level and HOMA-IR index was noted in the sucrose group compared to the normal control group. Administration of metformin $(P<0.01)$ and doses of $250(P<0.01)$ and $500 \mathrm{mg} / \mathrm{kg}(P<0.001)$ of CMAE resulted in a significant decrease in blood glucose compared to insulin resistance group. In addition, a significant $(P<0.001)$ decrease in serum insulin level and HOMA-IR was observed in rats receiving standard drug and different doses of CMAE. In addition, a significant $(P<0.001)$ decrease in serum insulin and HOMA-IR was recorded in rats receiving the standard drug and the different doses of CMAE.

Oral glucose tolerance test in insulin resistant animals The results shown in Table 3 indicate that, compared to the normal control group, administration of sucrose to normal rats resulted in a significant $(P<0.001)$ increase in blood glucose for 2 hours after D-glucose administration. Oral administration of metformin revealed a significant decline in glucose level at $60(P<0.01), 90(P<0.001)$ and $120 \mathrm{~min}(P<0.001)$ compared to disease control group. In addition, different doses of CMAE produced an important $(P<0.001)$ decrease in glycaemia at 60, 90 and $120 \mathrm{~min}$ after the glucose load.

\section{Effect of CMAE on lipid parameters}

Sucrose significantly $(P<0.001)$ increased TC, TG and LDL-c levels, and reduced HDL-c level compared to the normal control group (Table 4). Rats treated with 250 and $500 \mathrm{mg} / \mathrm{kg}$ of CMAE and metformin showed a significant $(P<0.001)$ decrease in TC, TG and LDL-c levels compared with untreated insulin resistance control. However, a significant increase in HDL-c was recorded in rats receiving the standard drug $(P<0.05)$ and CMAE

Table 2. Effect of Combretum molle on blood glucose level, serum insulin and HOMA-IR index in insulin resistant rats

\begin{tabular}{lcccc}
\hline Groups & Normal control & Disease control & $\begin{array}{c}\text { Suc + Met } \\
\mathbf{4 0} \mathbf{~ m g / k g}\end{array}$ & $\begin{array}{c}\text { Suc + Ext } \\
\mathbf{2 5 0} \mathbf{~ m g / k g}\end{array}$ \\
\hline Glucose $(\mathrm{mg} / \mathrm{dL})$ & $94.33 \pm 2.87$ & $118.67 \pm 2.95^{* * *}$ & $97.83 \pm 4.76^{\mathrm{b}}$ & $99.17 \pm 1.72^{\mathrm{b}}$ \\
Insulin $(\mu \mathrm{g} / \mathrm{L})$ & $0.24 \pm 0.00$ & $1.01 \pm 0.04^{* * *}$ & $0.68 \pm 0.04^{* * * c}$ & $0.45 \pm 0.06^{* * c}$ \\
HOMA-IR & $0.99 \pm 0.03$ & $5.31 \pm 0.22^{* * *}$ & $2.93 \pm 0.04^{* * * c}$ & $1.95 \pm 0.24^{* * c}$ \\
\hline
\end{tabular}

Data are the mean \pm SEM ( $\mathrm{n}=6$ in each group). ${ }^{*} P<0.05 ;{ }^{* *} P<0.01$ significantly different compared to normal control group. ${ }^{\mathrm{b}} P<0.01 ;{ }^{\mathrm{c}} P<0.001$ significantly different compared to disease control group. Sucrose + Metformin (Suc + Met), Sucrose + Extract (Suc + Ext), Homeostatic Model Assessment of Insulin Resistance (HOMA-IR). 
Table 3. Effect of Combretum molle on oral glucose tolerance test in insulin resistant rats

\begin{tabular}{|c|c|c|c|c|c|}
\hline \multirow{2}{*}{ Time (min) } & \multicolumn{5}{|c|}{ Blood glucose level (mg/dL) } \\
\hline & 0 & 30 & 60 & 90 & 120 \\
\hline Normal control & $94.33 \pm 2.87$ & $118.66 \pm 2.95$ & $97.83 \pm 4.76$ & $99.17 \pm 1.72$ & $91.67 \pm 2.81$ \\
\hline Disease control & $127.83 \pm 3.94$ & $156.33 \pm 3.04 * * *$ & $131.83 \pm 3.52 * * *$ & $133.83 \pm 2.69 * * *$ & $121.67 \pm 2.56 * * *$ \\
\hline Suc + Met 40 mg/kg & $122.00 \pm 3.30$ & $151.50 \pm 2.03$ & $121.67 \pm 2.75 a$ & $124.33 \pm 2.62^{c}$ & $111.33 \pm 4.11^{c}$ \\
\hline Suc + Ext 250 mg/kg & $117.50 \pm 3.08$ & $151.00 \pm 1.88$ & $109.50 \pm 2.35^{c}$ & $119.17 \pm 2.02^{\mathrm{c}}$ & $108.17 \pm 3.03^{c}$ \\
\hline Suc + Ext 500 mg/kg & $110.17 \pm 3.05$ & $145.67 \pm 1.84^{\mathrm{a}}$ & $103.33 \pm 4.57^{c}$ & $111.17 \pm 3.52^{\mathrm{c}}$ & $100.83 \pm 2.79^{c}$ \\
\hline
\end{tabular}

Data are the mean \pm SEM ( $\mathrm{n}=6$ in each group). ${ }^{* * *} P<0.001$ significantly different compared to normal control group. ${ }^{\text {a }} P<0.01 ;{ }^{b} P<0.01 ;{ }^{c} P<0.001$ significantly different compared to disease control group. Sucrose + Metformin (Suc + Met), Sucrose + Extract (Suc + Ext).

Table 4. Effect of Combretum molle on lipid parameters in insulin resistant animals

\begin{tabular}{|c|c|c|c|c|c|}
\hline Groups & Normal control & $\begin{array}{l}\text { Disease } \\
\text { control }\end{array}$ & $\begin{array}{l}\text { Suc + Met } \\
40 \mathrm{mg} / \mathrm{kg}\end{array}$ & $\begin{array}{c}\text { Suc + Ext } \\
250 \mathrm{mg} / \mathrm{kg}\end{array}$ & $\begin{array}{c}\text { Suc + Ext } \\
500 \mathrm{mg} / \mathrm{kg}\end{array}$ \\
\hline $\mathrm{TC}(\mathrm{mg} / \mathrm{dL})$ & $104.53 \pm 5.57$ & $210.55 \pm 5.06 * * *$ & $157.86 \pm 5.08^{c}$ & $167.77 \pm 9.93^{b}$ & $152.32 \pm 7.03^{c}$ \\
\hline $\mathrm{TG}(\mathrm{mg} / \mathrm{dL})$ & $90.01 \pm 3.97$ & $134.79 \pm 3.94^{* * *}$ & $109.38 \pm 4.44^{c}$ & $92.54 \pm 6.32^{c}$ & $97.51 \pm 3.99^{c}$ \\
\hline $\mathrm{HDL}-\mathrm{C}(\mathrm{mg} / \mathrm{dL})$ & $28.32 \pm 2.16$ & $11.51 \pm 1.45^{* * *}$ & $21.52 \pm 3.30^{\mathrm{a}}$ & $24.43 \pm 2.60^{b}$ & $23.65 \pm 2.40^{\mathrm{a}}$ \\
\hline LDL-C (mg/dL) & $58.21 \pm 5.21$ & $172.08 \pm 4.65^{* * *}$ & $114.46 \pm 3.96^{c}$ & $124.83 \pm 10.79^{c}$ & $109.16 \pm 6.10^{c}$ \\
\hline
\end{tabular}

Data are mean \pm SEM ( $\mathrm{n}=6$ in each group). ${ }^{* * *} P<0.001$ significantly different compared to normal control group. ${ }^{a} P<0.01 ;{ }^{b} P<0.01 ;{ }^{c} P<0.001$ significantly different compared to disease control group. Sucrose + Metformin (Suc + Met), Sucrose + Extract (Suc + Ext), Triglycerides (TG), Total cholesterol (TC), High-density lipoprotein cholesterol (HDL-C), Low-density lipoprotein cholesterol (LDL-C).

at the doses of $250(P<0.01)$ and $500 \mathrm{mg} / \mathrm{kg}(P<0.05)$ as compared to the sucrose group.

\section{Discussion}

Many studies have shown that a diet too rich in sucrose causes insulin resistance in rodents $(5,13,14)$, and therefore may affect the sugar and insulin metabolism (15). The mechanisms by which high fat and/or high sucrose diets cause insulin resistance are not fully understood. It has been shown that high sucrose diets may affect the metabolism of insulin and glucose. Preliminary phytochemical studies of aqueous extracts of CMAE showed presence of saponins, phenols, tannins, glycosides, flavonoids, and terpenoids (16). In this work, administration of sucrose in normal rats resulted in a significant increase in blood glucose, glucose intolerance, serum insulin, HOMA-IR, and lipid parameters.

The results showed that the body weight of the animals receiving the dose of $500 \mathrm{mg} / \mathrm{kg}$ of CMAE decreased significantly at the 20th and 30th days of treatment. This decrease in body weight could be due to the presence in the extract of chemical compounds such as tannins and saponins. It is documented that tannins have antinutritional properties and therefore, they can lead to loss of body weight, either by complexing proteins in the intestinal lumen (17) or by reducing food consumption (18). Significant decrease in food consumption observed at the last day of treatment in animals receiving different doses of extract partly confirms the observed weight loss.

In this study, CMAE significantly reduced blood glucose, serum insulin, and HOMA-IR compared to untreated sick rats. According to the results of our study, CMAE (250 and $500 \mathrm{mg} / \mathrm{kg}$ ) may enhance glucose intake in tissues, improve insulin resistance, increase insulin sensitivity and glucose uptake in rats in which insulin resistance was induced by a sucrose solution (19).

On the other hand, different doses of CMAE significantly decreased glycaemia from the $60^{\text {th }} \mathrm{min}$ after glucose load. These results suggest that CMAE can improve glucose intolerance and to effectively regulate postprandial glucose.

The oral administration of high sucrose in normal rats led to the dyslipidemia, characterized by high plasma concentrations of TC, TG and LDL-c with low plasma levels of HDL-c $(20,21)$. Results of this study indicate that, CMAE administered during 30 days reduced TC, TG and LDL-c, and increased serum concentration of HDL-c. CMAE could therefore potentially reduce cardiovascular complications under insulin resistance conditions. Moreover, since hyperlipidemia interferes with the absorption of sugar in the muscles, CMAE could stimulate the absorption of glucose by this muscle tissue (22).

Glycosides, flavonoids and phenols in plants would reduce hyperglycemia and hyperlipidemia in insulinresistant rats (23). The effects of insulin sensitization, anti-hyperglycemia, and anti-hyperlipidemia noted in this study may be due to the presence of these chemicals in the CMAE.

\section{Conclusion}

From this study, we can conclude that CMAE has insulin sensitizing and anti-hyperlipidemia potentials in high sucrose-induced insulin resistant rats. CMAE may prevent target tissue resistance to insulin action and thus reduce the risk of developing type 2 diabetes and its cardiovascular complications. 


\section{Acknowledgement}

The authors are thankful to Higher Teachers' Training College, University of Maroua, Cameroon, for providing the facility to carry out the research.

\section{Authors' contributions}

GT helped harvest and identification of plant material. $\mathrm{AD}$ proposed plant material and provided the reagents for the realization of phytochemical screening. DM and $\mathrm{AD}$ prepared the crude extract and conducted the phytochemical test. DM and SLPK drafted the article. DM performed the toxicological and antidiabetic tests and analyzed the data. SLW and AK corrected the final manuscript. All authors approved the final version of the manuscript

\section{Conflict of interests}

The authors declare no conflict of interest.

\section{Ethics considerations}

Prior authorization for the use of laboratory animals was obtained from the Cameroon National Ethics Committee (Ref. N. FWIRB 00001954).

\section{Funding/Support}

None.

\section{References}

1. Ohnogi H, Hayami S, Kudo Y, Deguchi S, Mizutani S, Enoki $\mathrm{T}$, et al. Angelica keiskei extract improves insulin resistance and hypertriglyceridemia in rats fed a high-fructose drink. Biosci Biotechnol Biochem. 2012;76(5):928-32. doi: 10.1271/bbb.110927.

2. International Diabetes Federation. Diabetes Atlas. 2nd ed. Brussels, Belgium: International Diabetes Federation; 2003.

3. Diagnosis and classification of diabetes mellitus. Diabetes Care. 2010;33 Suppl 1:S62-9. doi: 10.2337/dc10-S062.

4. World Health Organization (WHO). Global report on diabetes. Geneva: WHO; 2016.

5. Fried SK, Rao SP. Sugars, hypertriglyceridemia, and cardiovascular disease. Am J Clin Nutr. 2003;78(4):873s-80s. doi: $10.1093 / \mathrm{ajcn} / 78.4 .873 \mathrm{~S}$.

6. Laville M, Nazare JA. Diabetes, insulin resistance and sugars. Obes Rev. 2009;10 Suppl 1:24-33. doi: 10.1111/j.1467789X.2008.00562.x.

7. Surya S, Salam AD, Tomy DV, Carla B, Kumar RA, Sunil C. Diabetes mellitus and medicinal plants-a review. Asian Pac J Trop Dis. 2014;4(5):337-47. doi: 10.1016/S22221808(14)60585-5.

8. Choi SB, Park CH, Choi MK, Jun DW, Park S. Improvement of insulin resistance and insulin secretion by water extracts of Cordyceps militaris, Phellinus linteus, and Paecilomyces tenuipes in 90\% pancreatectomized rats. Biosci Biotechnol Biochem. 2004;68(11):2257-64. doi: 10.1271/bbb.68.2257.

9. Bessong PO, Rojas LB, Obi CL, Tshisikawe MP, Igunbor EO. Further screening of Venda medicinal plants for activity against HIV type 1 reverse transcriptase and integrase. Afr J Biotechnol. 2006;5(6):526-8.

10. Njume C, Afolayan AJ, Samie A, Ndip RN. Inhibitory and bactericidal potential of crude acetone extracts of Combretum molle (Combretaceae) on drug-resistant strains of Helicobacter pylori. J Health Popul Nutr. 2011;29(5):43845. doi: 10.3329/jhpn.v29i5.8897.

11. Mtunzi F, Singo T, Pholosi A, Mzinyane N, Modise J, Sipamla A. Investigation of the nutritive value and mineral elements of Combretum molle leaves. Pak J Nutr. 2012;11(2):176-80. doi: 10.3923/pjn.2012.176.180.

12. Ojewole JA, Adewole SO. Hypoglycaemic effect of mollic acid glucoside, a lalpha-hydroxycycloartenoid saponin extractive from Combretum molle R. Br. ex G. Don (Combretaceae) leaf, in rodents. J Nat Med. 2009;63(2):11723. doi: 10.1007/s11418-008-0298-0.

13. Ryu MH, Cha YS. The effects of a high-fat or high-sucrose diet on serum lipid profiles, hepatic acyl-CoA synthetase, carnitine palmitoyltransferase-I, and the acetyl-CoA carboxylase mRNA levels in rats. J Biochem Mol Biol. 2003;36(3):312-8.

14. Gonsolin D, Couturier K, Garait B, Rondel S, NovelChate V, Peltier S, et al. High dietary sucrose triggers hyperinsulinemia, increases myocardial beta-oxidation, reduces glycolytic flux and delays post-ischemic contractile recovery. Mol Cell Biochem. 2007;295(1-2):217-28. doi: 10.1007/s11010-006-9291-7.

15. Miaffo D, Kamani Poualeu SL, Kamanyi A. Antidiabetic activity of the methanol and acetone extracts of twigs of Combretum molle in dexamathasone induced-insulin resistance in rats. World J Pharm Sci. 2014;2(9):955-65.

16. Carbonaro M, Grant G, Pusztai A. Evaluation of polyphenol bioavailability in rat small intestine. Eur J Nutr. 2001;40(2):84-90. doi: 10.1007/s003940170020.

17. Oliveira AC, Endringer DC, Amorim LA, das Gracas LBM, Coelho MM. Effect of the extracts and fractions of Baccharis trimera and Syzygium cumini on glycaemia of diabetic and non-diabetic mice. J Ethnopharmacol. 2005;102(3):465-9. doi: 10.1016/j.jep.2005.06.025.

18. Ehsanifard Z, Mir-Mohammadrezaei F, Safarzadeh A, Ghobadnejhad M. Aqueous extract of Inocutislevis improves insulin resistance and glucose tolerance in high sucrose-fed Wistar rats. J Herbmed Pharmacol. 2017;6(4):160-4.

19. Ghafoorunissa, Ibrahim A, Rajkumar L, Acharya V. Dietary (n-3) long chain polyunsaturated fatty acids prevent sucrose-induced insulin resistance in rats. J Nutr. 2005;135(11):2634-8. doi: 10.1093/jn/135.11.2634.

20. Pagliassotti MJ, Gayles EC, Podolin DA, Wei Y, Morin CL. Developmental stage modifies diet-induced peripheral insulin resistance in rats. Am J Physiol Regul Integr Comp Physiol. 2000;278(1):R66-73. doi: 10.1152/ ajpregu.2000.278.1.R66.

21. PagliassottiMJ,Prach PA, KoppenhaferTA, PanDA. Changes in insulin action, triglycerides, and lipid composition during sucrose feeding in rats. Am J Physiol. 1996;271(5 Pt 2):R1319-26. doi: 10.1152/ajpregu.1996.271.5.R1319.

22. Corcoran MP, Lamon-Fava S, Fielding RA. Skeletal muscle lipid deposition and insulin resistance: effect of dietary fatty acids and exercise. Am J Clin Nutr. 2007;85(3):662-77. doi: 10.1093/ajcn/85.3.662.

23. Kianbakht S, Hajiaghaee R. Anti-hyperglycemic effects of saffron and its active constituents, crocin and safranal, in alloxan-induced diabetic rats. J Med Plants. 2011;3(39):829. [Persian]. 